\title{
From family to workplace: How the adult attachment styles affect leader-subordinate relational identity?
}

\section{Sung-Chun Tsai}

National Taipei University of Education

\section{Introduction}

The issue of how relational identity about leader-subordinate affects each other's behavior is getting attentions. We took perspective of social cognitive schema to clarify the dimensions and contents of the leader-subordinate relationship. By using two dimensions of "equal/unequal" and "close/distant", the contents of the leader-subordinate relational identity (LSRI) are classified into four categories: communal affection RI (equal and close), instrumental exchange RI (equal but distant), carerepay RI (unequal but close), and authority-obedience RI (unequal and distant). The present study thus chose communal affection relationship (CARI) and care-repay relationship (CRRI) proposes to probe this critical issue. First, the study will explore how the adult attachment styles effect the CARI and CRRI. Second, it will explore if the relationship between the adult attachment styles and CARI/CRRI is mediated by stimulus generalization. It purpose was to understand why the adult attachment styles with parents can transfer to leaders with the perspective of pan-familism. To clarify the relationship between family and the workplace of the two fields.

\section{Pan-familism theory}

> Taiwanese individuals were likely to generalize the interactive styles,

$>$ such as affectionate relationships, behaviors, and values acquired in their families to other social organizations and shaped the different relational identities.

$>$ In the workplace situations, such relational schema would serve as a source of evaluation to guide the leader-subordinate exchange on both sides.

Sample Method
We collected a total sample of 166 employees data in Taiwan. Of those, $33.7 \%$ were female, average age was $26-$ 40 years old $(50.6 \%), \quad 63.2 \%$ had bachelor's degrees.

\section{Measures}

Adult Attachment Style.Revised Fraley, Waller, and Brennan (2000) Experiences in Close Relationships-Revised.

26-item scale $(\alpha=.61)$

LSRI. Tsai and Cheng's (2012) scales.

Communal affection RI. 5-item $(\alpha=.82)$

Instrumental exchange RI. 5-item $(\alpha=.83)$ Care-repay RI. 5-item $(\alpha=.87)$

Authority-obedience RI. 4-item $(\alpha=.89)$

Stimulus Generalization. Tsai (2006) scales. 5-item $(\alpha=.78)$

Controls. Gender, age, education, length of cowork.

\section{Result}

\section{Main Effects}
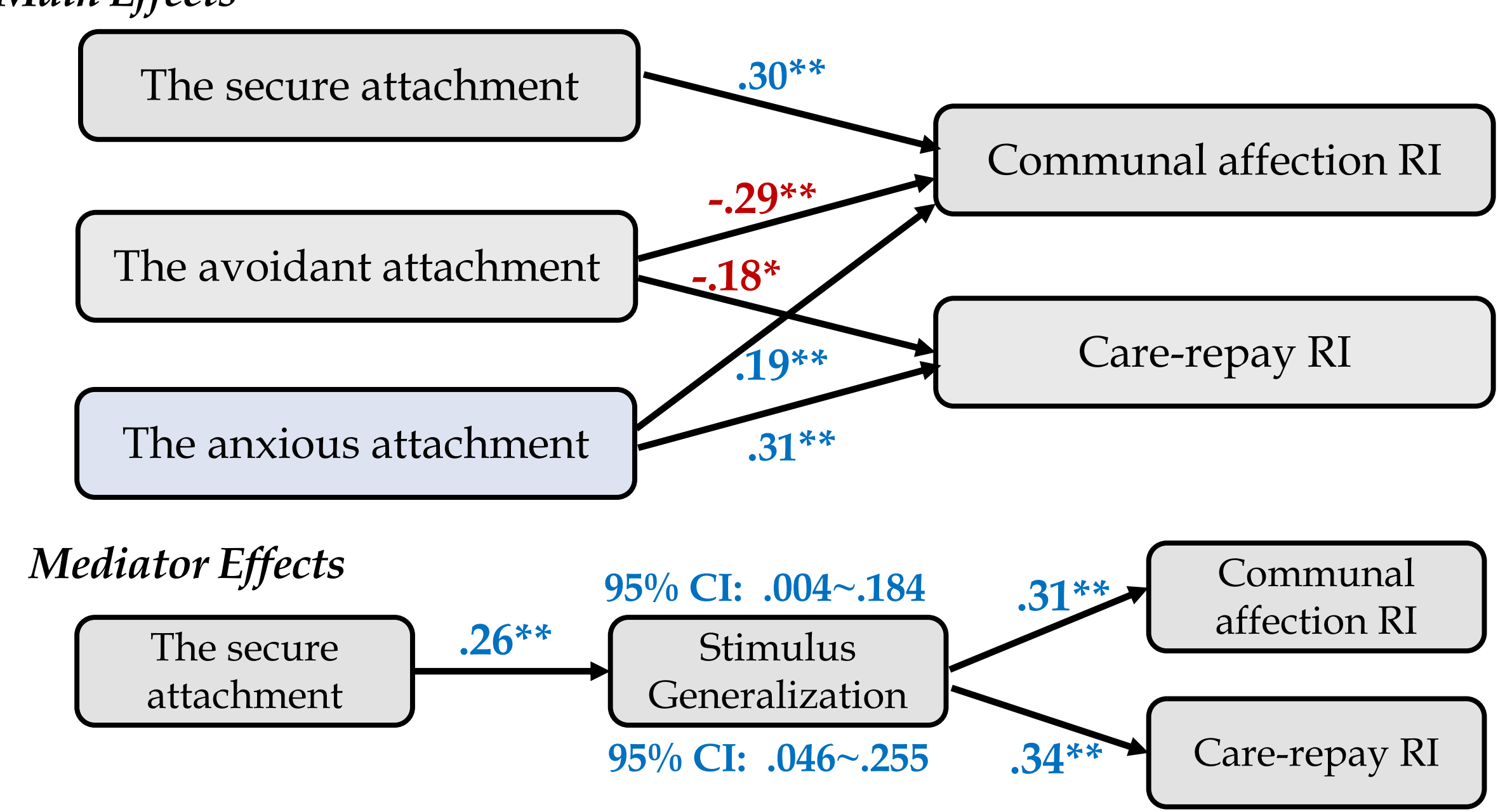

The results of regression analysis showed:

$\checkmark \quad$ The adult attachment is significantly related to subordinates' LSRI.

$\checkmark$ The secure attachment is positively related to subordinate's communal affection RI.

$\checkmark \quad$ The avoidant attachment was negatively associated with CARI and CRRI.

$\checkmark \quad$ The anxious attachment was positively associated with CARI and CRRI.

$\checkmark \quad$ The results of bootstrap method analysis showed: Stimulus generalization plays the full mediator role for the prediction from the secure attachment to CARI and CRRI.

\section{Discussion}

\section{Theoretical Contribution}

$>$ Supported the LSRI model and pan-familism theory.

> Clarified how adult attachment affects subordinate's leader-subordinate relational identity. 